\title{
Does the teaching of thinking promote language acquisition?
}

\section{Carol A. Puhl}

Combining the teaching of thinking skills and a second language seems a plausible way to promote language acquisition. The teaching of thinking is explained, with an example from the curriculum of de Bono. Arguments supporting the thinking-L2 combination come from theory, practice, its benefits to teaching skills, national needs, and successful implementation. Research literature is reviewed, and a major study in South Africa is summarized.

Die kombinasie van die onderrig van denkvaardighede en tweede taal blyk 'n aanneemlike metode om taalverwerwing te bevorder. Die onderrig van denke word aangedui, met ' $n$ voorbeeld uit die kurrikulum van De Bono. Argumente wat die kombinasie van denke en tweede taal ondersteun, word gebaseer op teorie, praktyk, voordele vir onderwysvaardighede, nasionale behoeftes, en suksesvolle toepassing. Navorsingsartikels word in oënskou geneem, en 'n belangrike navorsingstudie word opgesom.

\section{INTRODUCTION}

The question of whether the teaching of thinking promotes language acquisition is a hypothesis under research, both in classroom practice, and in scientific measurementbased studies. There is interest world-wide in improving one's thinking, and in such a multilingual country as South Africa there is always interest in language teaching and learning. Combining language and thinking seems a powerful and efficient way to improve curriculum at many levels, to ensure relevance, and to let the two components enhance each other in an educational endeavour that is greater than the sum of its parts.

The history of each one alone is centuries long. A formal concern with thinking goes back at least to the ancient Greeks, with their logic, philosophy, geometry, and their inquiry approach to knowledge. Language is as old as the human race, and the mastery of other languages defined the educated person up to modern times. Languages still occupy a considerable part of the school day in South Africa, with many pupils studying their mother tongue as a subject, plus one or both of the official languages. When an L2 becomes the medium of instruction, language study indirectly occupies an even greater part of the school day. With the advent of mass education, more subjects have been included that are practical, though still not even yet practical enough. Indeed, the chairman of Eskom, J.B. Maree, noted in his 1990 annual report the lack of fit between the educational system, which is academically oriented, and the market place, which requires technical and practical skills, resulting in a shortage of skilled people as well as an abundance of people without jobs (Maree 1990). 
The idea of joining the teaching of a second language and the teaching of thinking skills strikes one as eminently practical, all the more so if the thinking skills do indeed foster language acquisition, as hypothesized. Actually, the idea is quite plausible. In 1987 van der Vyver presented a proposal entitled "English and operacy for teachers". (The term operacy has been coined to parallel the terms literacy and numeracy, and it refers to skill' in using one's intelligence, or thinking.) The study has been completed (Odendaal et al., in press), and it is summarized later in this paper. To explore further how thinking skills can enhance L2 acquisition, it is necessary to clarify what is meant by thinking skills.

\section{DEFINITION OF THINKING SKULLS}

\subsection{Leaders in the field}

Among the leading proponents of the teaching of thinking skills are Edward de Bono (1986, 1976) of the Cognitive Research Trust (CoRT), UK; David Perkins (Nickerson, Perkins \& Smith 1985; Perkins \& Salomon 1989) of Harvard University; Raymond Nickerson and Edward Smith (Nickerson, Perkins \& Smith 1985) of Bolt Beranek \& Newman Inc., Cambridge, Massachusetts; Robert Sternberg (1987) of Yale University; Reuven Feuerstein (Feuerstein \& Jensen 1980), Hadassah-WIZO Canada Research Institute, Jerusalem; and Dr. Luis Alberto Machado (in Nickerson et al. 1985), former Minister of Human Intelligence, Venezuela. The considerations that follow draw mainly, though not exclusively, upon the work of these leaders.

According to de Bono, "Thinking is the operating skill through which intelligence acts on experience" (1976:33). If one thinks of intelligence as a person's latent potential, then thinking can be viewed as skill at using that potential. While intelligence in an educational sense is usually thought of as a stable natural gift of mind which is inborn, and which can be determined to some extent as a rather fixed quotient, thinking skill is something else again. It is viewed as a skill that can be learned, applied, developed, and put to conscious, deliberate use. It is often used in the plural to denote a variety of thinking skills, each with its own focus, for the purposes of directing attention and clarifying perception. Thinking in the traditional sense refers to logic, to well-founded argument and supported assertion, to "critical thinking". Thinking skills refer to mediation, to putting one's mind between input and output, to the activity that makes the difference between behaviour that is impulsive or based on reaction, and behaviour that is systematic, or based on deliberate use of mind, feeling, and will. A person using thinking skills to solve a problem will not take the first solution as the only one and then put energy into defending that choice. Such a person will broaden his or her perceptions of the problem, possibly define requirements of a solution, come up with alternatives, and choose the best one(s). It is at the latter stage of the process that critical thinking comes in, while thinking skills are more likely to enter at the beginning, at the perception stage of the thinking process. Critical thinking and thinking skills are not inherently contradictory; they merely emphasize different aspects of a unitary process. Thinking skills are particularly useful because, according to de Bono (1976), most mistakes in thinking are made at the perception level, and if people could broaden their perception at the start, they could improve their thinking by preventing mistakes which limit them too soon.

\subsection{Approaches to the teaching of thinking}

Over 20 approaches are reviewed and evaluated by Nickerson, Perkins, and Smith (1985) in their book The Teaching of Thinking. Additional approaches are noted in the studies reviewed later. Some approaches are specific to a field, such as science, or to a target 
group of learners, such as mentally disabled learners, while other approaches are more general. The issue of general versus specialist skills is discussed by Perkins and Salomon (1989). It is the general approach which seems most useful to educationalists, especially those responsible for curriculum, and among the most accessible is that of de Bono, whose approach has been well developed in its application in classrooms over the past two decades. According to Edwards (1990), de Bono's approach is one of the two most widely used world-wide. The other approach in widest use is that of Feuerstein (with Jensen 1980), who focuses on children with special problems. A more detailed look at de Bono's work can serve as an example of approaches to the teaching of thinking.

\subsection{The CoRT Approach}

In his CoRT materials in Books 1-6, de Bono presents a systematic compilation of 60 thinking skills, also called tools, under six divisions: Tools for Breadth, Organization, Interaction, Creativity, Information and Feeling, and Action. The first to be taught are the Breadth Tools (CoRT 1), after which the sequence does not matter. The purpose of the breadth tools is to provide as comprehensive a view of the subject or problem as is feasible. For example, the tool called Positive, Negative, and Interesting (PNI for short) invites users to look at the points in favour, the points against, and the interesting (neither for nor against) points of an idea, suggestion, or proposal. A common reaction to an idea or suggestion is "I like it", in which case the person finds positive aspects of the idea, and perhaps neglects to see negative ones. The same is true of negative reactions, in which positive points may be overlooked. Using the PNI gives people a way to transcend their first reactions. Their focus changes from emotion to carrying out a formal operation. The PNI, like the other tools, is not designed to prevent commitment or action, but to make sure that action is taken only after various aspects of a suggestion have been considered, and not before. The consideration need not be a lengthy process; it just must be done to get the benefit of the tool. Another example from the first set of CoRT tools is Consider All Factors, or CAF for short. While PNI helps one organize a response to an idea, CAF helps a person to explore a situation before coming up with an idea. CAF re-directs attention from the importance of the factors to a search for all factors. Then decisions can be made on relative importance. People typically consider the obvious factors of a situation, when sometimes the non-obvious ones turn out to be critical. Other People's Views, OPV, another CoRT 1 tool, helps learners to make a deliberate attempt to see a situation as another person might see it. This view can then be taken into account in a decision, or it might even provide a whole new way of seeing the situation. Certainly it helps learners to realize that their viewpoint is not the only one. Actually, the OPV represents a profound skill that is essential for human communication to take place at all (G.H. Mead, in Littlejohn 1978).

The above examples of thinking skills, PNI, CAF, and OPV, show that the use of thinking skills is an attempt to crystallize the process of bringing one's intelligence to bear on a specific situation or problem. The skills direct attention which otherwise may be diffused. They provide a clear, crisp "handle" with which to remember the skill, apply it to new situations, and thus focus one's knowledge in a certain way and for a certain purpose. These breadth tools capture an attitude of open-mindedness and summarize it into an action. Far from limiting one's thinking, the tools provide a structure which enables the thinker to do more than without the tool. De Bono (1986) compares using thinking tools to using tools such as a cup, a ladder, a lawn-mower, and notation; they are liberating structures which make it easier for us to do the things we want to do, things that are in our interest to do.

The other thinking tools in CoRT 1 are Rules; Consequences and Sequels (C \& S); Aims, Goals, and Objectives (AGO); Planning; First Important Priorities (FIP); Alternatives, Possibilities, and Choices (APC); and Decisions. Their very names give an idea of the focus of each tool. The other clusters of CoRT tools have other specific objectives, and 
can be selected depending on what one wants and needs to accomplish. Use of CoRT in schools has been studied by Edwards (1990, 1988 and earlier), who found consistent improvement in academic performance of CoRT-trained students compared to control groups. He found high gains in language arts and social science as a result of learning CoRT tools. Having considered a definition of thinking skills and an example, it is appropriate to discuss reasons that such skills can be included in the L2 curriculum.

\section{RATIONALE FOR INCLUDING THINKING SKILLS IN THE L2 CURRICULUM}

A revision of the language curriculum is proposed that combines the teaching of language with the deliberate teaching of thinking skills. Five main reasons for this combination have been identified.

\subsection{Theory supports such a combination}

It is generally accepted that there is a close connection between language and thought. A summarized discussion can be found in Boyle (1987), in which he contrasts the views of Oller and Carroll, two leaders in the field of L2 teaching and learning. Oller claims that language and thought are identical. The more prevalent view is expressed by Carroll, who holds that language and thought, while not equivalent, are very close. Such discussions hinge of course on how language and thinking are defined and operationalized. It is clear that some kind of language, whether verbal or nonverbal, is necessary for thought to go very far. At the same time, an expanded conceptual system including vocabulary goes along with the expansion of thought. This close connection can be used to make thinking its own reason for learners to practise using the code they have mastered, and to reach for new mastery through peer interaction. (The teaching of thinking, obviously, is not best accomplished by the lecture method.) Students will hear words, phrases, and sentences to express ideas, they will want and need to express their own ideas, and they will reach out to find and use words, phases, sentences, etc. The very closeness of language and thinking makes the combination in the classroom a natural one. It may be helpful to distinguish in passing between "thought" and "thinking" in the present context, where "language and thought" connotes abstraction at a deep cognitive level, while "language and thinking" connotes concepts made operational, even practical and immediately useful. The transfer of thinking skills to language arts has been noted by de Bono (1976), who finds it reasonable to expect that such transfer should take place. This transfer has been studied and supported by Edwards (1990).

\subsection{Practice supports combining the teaching of thinking skills and language}

Thinking skills and linguistic communication share a common ground in method, where they are best taught by pair and group interaction. They can both utilize communication in the classroom. Except for a short time when each must be explained, as a skill or as a principle, the focus of both is on meaning, not form. Just as one cannot think without using some form of symbolic representation, usually words, the traditional language skills of listening, speaking, reading, and writing are used in the teaching of thinking. Both thinking skills and language involve problem-solving. Because good language teaching generally requires some type of issue-oriented or problem-solving activity, this combination is a natural one. But thinking skills involve more than problem-solving. Such skills, identified, named, and defined as they are, become focused strategies with applicability that is wider than a few problem-solving situations. These skills are taught explicitly in themselves, in the target language, and all the while using the target 
language for the practice of these strategies in problem-solving, which gives then also practice in language use. It is widely accepted that the best way to develop proficiency in a language is to use it in an authentic way, to achieve non-linguistic goals. Hence practice in language and thinking becomes one and the same. This is why the hypothesis that the teaching of thinking promotes $\mathrm{L} 2$ acquisition is plausible.

Their combination leads to an efficient use of classroom time, so that in a way two skills are learned in the time usually allocated to one. With class time always limited, efficiency in the classroom is a high priority.

\subsection{The teaching of thinking skills can improve teaching skills in general, and language teaching skills in particular}

Combining the teaching of thinking and language fosters communicative language teaching. Besides pair and group interaction, or perhaps as a consequence of such interaction, teaching becomes more learner-centred. Because the learner must be thinking, he or she must be active rather than passive. Activity in class usually leads to greater motivation. In this type of classroom, rote leaming is neither desirable, rewarded, or even possible, and it must give way to more meaningful education. There is less dependence on authority for the "right" answers, and more willingness of learners to take the initiative and the responsibility for their learning. A classroom like this promotes behaviours such as learners listening to one another as well as to the teacher. It promotes the synthesizing of ideas, dealing with agreement and disagreement, learning how to have differences without strife. It promotes a healthy classroom climate of respect for all, of working together, of co-operative attitudes and skills. Benefits to the learners can include increased self-confidence of the learners (found by Edwards 1990), heightened selfesteem, and greater personal empowerment. Positive effects on the teacher have been demonstrated (Clayton \& Edwards 1989, in Edwards 1990). In a sense, the use of mind is not limited to the degreed few, but rather it becomes democratized, which is in the interests of a democratic nation. It is enabling; as the ancient writer Virgil said, "I can because I think I can".

\subsection{Combining the two will meet many of the educational needs of South Africa}

\section{as a developing country with a $50 \%$ literacy rate}

According to the World Bank as an authority on what leads to development, the biggest return on investment in education will come from improvement and expansion at the primary school level (Moulder 1990). The need for an excellent, relevant, practical curriculum is obvious. It is here that the teaching of language, especially English L2 in Department of Education and Training schools, must be accomplished, and the most effective and efficient language methodology is urgent. In these schools, instruction changes from the medium of mother tongue to English in the fifth year, and studies have shown that children leave in droves, in large part because they (and often their teachers as well) cannot cope with what is expected of them in the medium of English (Thembela 1989). In this situation English proficiency is needed across the curriculum. With subject textbooks in English, children cannot be expected to function successfully in their other subjects unless they can function in the medium of those subjects, English. Without literacy, as Moulder (1990) points out, people cannot read an instruction manual, for example to install equipment. They cannot take correspondence courses. They cannot develop the skills the country needs, and they cannot for the most part improve their lives in terms of a modern economy. Improving the English L2 curriculum will go a long way toward improving education, especially at primary level. 
The need for improved education is not limited to primary schools; it is pervasive. It is articulated regularly in the media. In a 1989 survey of 379 members of the Chamber of Commerce, the respondents blamed the educational system for producing employees who do not have the ability to think for themselves (Bosch 1990). The prescriptiveness of the educational system does not foster thinking and initiative, they felt. Besides emphasising more practical subjects, including communication, the survey respondents were greatly concerned about the appallingly low level of spelling and grammar in both official languages. Because people cannot think, use language, or communicate well enough, business must spend "huge sums", as they phrased it, to retrain new employees, adding to costs and reducing productivity. A relevant curriculum (curriculum as used here includes syllabus, method, and evaluation) is a vital chip in the educational circuitry that aims to produce citizens who are basically functional in a modern setting, who can seek realistic personal fulfilment through work, and who have useful skills to bring to the country's economy. Combining the teaching of thinking along with language is certainly one way to address those needs.

A further way that such a curriculum will meet the needs of South Africa is that the teaching of thinking skills is designed to lead to a democratization of intelligence (van der Vyver \& Capdevielle 1989). The goal is to produce a nation of thinkers who are still practical, who have communication skills, and who have the idea that they can make a contribution as well as how to go about doing so. This is crucial for the new South Africa that is in the process of being born.

It might be noted in passing that the need for language and thinking skills is not unique to South Africa. One of the most frequently cited factors for the failure of American education is lack of students' ability to read and think critically, and the National Commission on Excellence in Education recommends that all school subject areas, including languages, help students to develop thinking abilities (in Sacco 1987). In Venezuela in 1979, a national "think tank" group decided that the best way to improve Venezuelan education was through the teaching of thinking. It was made a national educational priority, with curriculum materials written jointly by Venezuelans and Harvard University scholars in thinking. Studies and implementation followed, reviewed in Nickerson et al. (1985), with significant positive results.

\subsection{Combining the teaching of thinking and $L 2$ has been shown to be effective in the South African setting}

The Institute for Language Teaching (INTUS) has implemented and researched this combination in South Africa in several of its projects. One such study deals with thinking and English L2 taught to mine workers (Puhl 1990) and to pre-university students (Puhl \& Swartz 1989). This approach has been used combining thinking and Afrikaans L2 for business people (INTUS 1989) and for higher-primary pupils (Blanckenberg, in progress). The most comprehensive project to date is the one by Odendaal et al. (in press) entitled English and Operacy for Primary School Teachers. An overview is given later in this paper. It is useful at this point to examine what study has been done on the teaching of thinking and language combined. 


\subsection{Thinking and Language}

The literature on the teaching of thinking is growing (citations above). Books and articles on teaching second languages and on teaching thinking, each on its own, are readily available. However, research on teaching a combination of thinking skills and L2 is not easily found. A computerized search of the ERIC database from 1966 to March 1990 yielded 30 relevant articles, papers, and materials. Of these 30, 26 connected thinking with $\mathrm{L} 1$, and only 4 connected thinking with $\mathrm{L} 2$. Most of the studies described thinking skills as "critical thinking" or "higher-order thinking", sometimes as "creative thinking". The levels range from primary to higher education. Thinking skills are taught mainly in the language arts or reading class, though some are joined with writing, listening, and speaking. (A few studies were found which linked thinking skills and the teaching of science, social studies, mathematics, and even music, and these studies may be of interest to curriculum developers of those subjects. One study proposes thinking across the curriculum.) One article notes perception and evaluation, and most others give ways to integrate thinking into the language curriculum. The four L2 thinking studies are discussed in detail.

\subsection{Thinking and $\mathrm{L} 2$}

Harper and Lively (1988) have developed five units of instruction combining vocabulary and "higher-order thinking skills" for foreign language instruction in two-year tertiary institutions. Language activities, on the topics of types of buildings, rooms of a house, vacation clothing, foods, colours, sizes, and shapes, were built around clearly-identified thinking skills. Examples of the skills include classifying, verifying, hypothesizing, determining cause and effect, seeing consequences, drawing conclusions, comparing, decision-making, and imagining. In another study, Rodriguez (1986) has examined the use of analogies for improving thinking skills of students who were learning English and L2. Sacco (1987) outlined "an approach to developing critical-reading and thinking skills in the foreign language curriculum" based on the change from memorization, translation, and discrete-point testing to communicative teaching and testing, with its emphasis on problem-solving. The skills range from beginning-level ones, which he defines as the thinking skills required to persuade an audience, accept or refute messages, analyze simple texts, and use language creatively, to more advanced skills, defined as those required for a student to "detect and evaluate cultural information, stereotypes, myths, and overgeneralizations"; critique texts; note an author's style and tone in literature; and compose and interpret business letters and memos. The approach has three main objectives: to cultivate in the students a healthy scepticism, to help them develop a critical eye, and make them more sensitive to language in use. Terrio (1986) argues that writing, by integrating L2 learning, should lead to better thinking in both $\mathrm{L1}$ and L2. The example is given of a tertiary curriculum in French which includes among its activities sentence-combining, critical text reading exercises, and keeping a dialectical joumal. Terrio shows how guidelines for rating oral proficiency promote cognitive skill development.

Of the four studies, the first two relate clearly-identified thinking skills to L2 (the generalist approach), and the last two use thinking skills highly contextualized into language activities (the specialist approach). Perkins and Salomon (1989) discuss this difference in terms of the degree of contextualization of thinking instruction. In the above studies, thinking skills are clearly visible in the first two and hardly perceptible per se in 
the latter two. The low number of studies available, and their late-1980's dates, indicate that work in combining thinking and language instruction is still beginning.

\subsection{English and operacy for primary school teachers}

The Institute for Language Teaching (INTUS) has conducted research on its various teaching projects, cited above, integrating thinking skills into second-language materials. This approach keeps the skills visible, so that they can be retrieved and consciously applied in situations far beyond the language classroom. (A similar approach can be taken in other school-subject areas.) The major experimental study to date, English and Operacy for Primary School Teachers, was sponsored by the privately-funded UPTTRAIL Trust, whose purpose is to improve education where the need is greatest, primarily the English proficiency of children in Department of Education and Training (formerly "black") schools. The Human Sciences Research Council contributed to the research design, monitored the implementation of the experiment, analyzed the statistics, and reported on the data. Finally, an international academic panel conducted a metaevaluation of the entire research effort.

In the study forty-eight classrooms in KwaZulu involving about 2200 pupils were randomly selected, 36 as experimental and 12 as control. In January 1989 , the teachers in the experimental group were given three weeks of training in L2 methodology and the teaching of thinking skills (details below), along with training to improve their own English and thinking skills. In order to control the training variable, teachers in the control group were also given training, but of a more specific nature, in how to use interactive group techniques when they give L2 classes. The content of the training received by the experimental-group and by the control-group teachers was different.

When the pupils arrived for the 1989 school year, control classes received their teaching as usual, albeit with slightly better-trained teachers, while the experimental classes were given their English classes for the year using the INTUS approach in a curriculum combining the teaching of English L2 and thinking skills. A text was specially written by Odendaal (1989) with a story of Themba and his young friends using thinking skills as they dealt with the challenges of life that came their way. The language teaching was based on suggestopedic methodology, which includes a communicative approach providing massive input, attention to affect, and pair and group work. Various techniques were used, including games to ensure active rather than passive learning, positive attitudes, relaxation, self-confidence, and techniques to draw the whole brain, indeed the whole person, into language learning. Many measures were utilized to determine changes in the pupils, including standardized tests and examination marks in English and other subjects. The results of these measures for the experimental groups were compared with results of these measures for the control groups. Analysis revealed substantial improvement in the English language skills of the pupils in the experimental groups over those of the control groups. Further, the experimental treatment had the effect of improving the pupils' performance in Social Studies, a subject which is heavily based on English language proficiency, with experimental groups out-performing control groups. These results were ascribed by the HSRC monitoring team to both the innovative teaching methods used by the teachers and to the course material, which included thinking skills (Mouton, Claassen, \& Strassheim, in press).

The thinking skills implemented in the curriculum were selected from CoRT 1. They were taught successfully by teachers with a minimum of training themselves, in the context of a story along with communicative practice. This study shows that an L2 curriculum which includes thinking skills has been effective and has made a substantial impact in addressing the needs of primary education in South Africa. While innovative methods must surely account for some of the success, the results lend at least partial empirical support to the hypothesis that teaching thinking can promote language 
acquisition. Further, the fact that English skills transferred spontaneously to Social Studies shows a significant benefit of good English teaching for other parts of the curriculum.

\section{CONCLUSION}

An instructional approach has been explored which combines the teaching of L2 with the teaching of thinking skills. The approach is supported with arguments from theory, from improvement to the teaching skills of teachers, from the needs of South Africa as a developing country, and from its demonstrated effectiveness. The main literature on the teaching of thinking was examined, and research was reviewed concerning studies that combine the teaching of language and thinking, especially with L2. Ongoing research in this area was examined and was carried out at the Institute for Language Teaching. If a new approach has been used with positive results, many of the difficulties have already been overcome, and a path has been opened for others at least to explore. Combining the teaching of thinking and L2 is a major way of using resources effectively and indeed of transforming the classroom as is so urgently needed worldwide. Combining the teaching of L2 and thinking can contribute to the development of the most effective curriculum possible. For South African and other countries as well, it is not a luxury but a necessity, an opportunity that must not be lost.

\section{BIBLIOGRAPHY}

BLANCKENBERG, COLLENA. Research in progress. The evaluation of curriculum development in an integrating communicative language teaching model. Stellenbosch: Institute for Language Teaching.

BOSCH, MARIUS. 1990. Huge sums go to retrain graduates. Cape Times, 17 April.

BOYLE, JOSEPH P. 1987. Intelligence, reasoning, and language proficiency. The Modern Language Journal, Vol. 71, No. 3, 277-288.

DE BONO, EDWARD. 1986. CoRT thinking: teacher's notes, breadth. New York: Pergamon Press.

DE BONO, EDWARD. 1976. Teaching thinking. Middlesex: Penguin Books.

EDWARDS, JOHN. 1990. The direct teaching of thinking skills. In Learning and Teaching Cognitive Skills, Glen Evans (Ed.) In press.

EDWARDS, JOHN. 1988. Effects of an intensive CoRT program on grade 7 students. Queensland, Australia: James Cook University of North Queensland.

FEUERSTEIN, REUVEN. 1980. Instrumental enrichment: theoretical basis, goals, and instruments. The Educational Forum, May.

HARPER, J. \& M. Lively. 1988. We've got the "H.O.T.S." for foreign languages: Higher order thinking skills. Hurst, Texas: Tarrant County Junior College. (ERIC document ED294641)

LITTLEJOHN, S.W. 1978. Theories of human communication. Columbus, Ohio: Charles E. Merrill Co. 
MAREE, J.B. 1990. Quoted in article: Eskom "inline" with budget. Sapa news service, Cape Town, 14 May.

MOULDER, JAMES. 1990. Learning from experience: Errors to be avoided in addressing the education crisis. Finance Week, 10-16 May, 42-43.

MOUTON, J., N.C.W. Claassen \& A. Strassheim. In press. English and operacy for primary school teachers: Part Two: A programme evaluation. Pretoria: Human Sciences Research Council.

NICKERSON, R.S., D.N. Perkins \& E.E. Smith. 1985. The teaching of thinking. Hillsdale, New Jersey: Lawrence Erlbaum Associates, Inc.

ODENDAAL, MARIE, H. Ludolph Botha, Johann Mouton, et al. In press. English and operacy for teachers.

ODENDAAL, M. 1989. Time to Fly. Stellenbosch: UPTTRAIL Trust.

PERKINS, D.N. \& G. Salomon. 1989. Are cognitive skills context-bound? Educational Researcher, Vol. 18, No. 1.

PUHL, CAROL A. 1990. Up from under: English training on the mines. Per Linguam Vol. 6, No. 2.

PUHL, CAROL A. \& J.J. Swartz. 1989. Designing a second-language bridging course for university students. Per Linguam, Vol. 5, No. 1, 17-32.

RODRIGUEZ, YOLANDA C. 1986. Analogies for improving thinking skills in English as a second language. Paper, Texas Women's University. (ERIC document ED284424)

SACCO, STEVEN J. 1987. Crap detecting: an approach to developing critical reading and thinking skills in the foreign language curriculum. Foreign Language Annals, Vol. 20, No. 1, 57-66.

STERNBERG, ROBERT J. (with J.B. Baron). 1987. Teaching thinking skills: theory and practice. New York: W.H. Freeman \& $\mathrm{Co}$.

TEMBELA, A.J. 1989. Black education in South Africa: issues, problems and perspectives. Per Linguam, Vol. 5, No. 1, 2-8.

TERRIO, S.J. 1986. Building critical thinking skills through writing in the foreign language classroom. Paper, Annual Meeting of the Northeast Conference on the Teaching of Foreign Languages. (ERIC document ED276263)

VAN DER VYVER, D.H. 1987. English and operacy for teachers. Per Linguam, Vol. 3 , No. 1, 1-4.

VAN DER VYVER, D.H. \& B. Capdevielle. 1989. Towards the mountain: characteristics and implications of the South African UPTTRAIL pilot project. Per Linguam Vol. 5, No. 1, 9-16. 